\title{
The Cop21 Agreement: A Giant Illusion?
}

\author{
Jan-Erik Lane ${ }^{1 *}$ \\ ${ }^{1}$ fellow with Public Policy Institute, Belgrade \\ *Jan-Erik Lane, E-mail: janeklane@gmail.com
}

\begin{abstract}
The policy sciences, enquiring into the making and implementation of public decisions, has made several stunning findings that are highly relevant to the COP21 Agreement or Treaty if you so wish. They constitute the so-called "implementation gap" or the "hiatus of policy implementation", analysed by late American Aaron Wildavsky and also Paul Sabatier. The enormous enthusiasm for the COP21 framework must be dampened when confronted with the lessons from policy implementation, especially in such an extremely decentralised approach taking place over so many years. But the signatories have to decide now how to halt the increase in greenhouse gases (GHG), especially the CO2:s in order to start decreasing them, hopefully (naively) to zero in 80 years. As the emergence of economically viable renewable energy is slow, the only quick solution is to remove coal as an energy source. That would resolve the star economist Jeffrey Sachs dilemma that decarbonisation would result in negative economic growth.
\end{abstract}

\section{Keywords}

$G H G, C O 2, G D P$, decarbonisation, energy types, global warming: $+1.5,+2,+2.7,+4,+6$, developing countries, advanced countries, halting emission growth, reducing emissions, country energy sources, the coal problematic: dismantling and massive filtration

\section{Introduction}

The governments, the IGO:s and NGO:s and other experts on climate change will hear that halting or reducing the emission of GHG:s must involve costs. There are simply not enough alternative energy sources or innovations to draw upon, at the moment. Some countries will ask for special delays, others will call for economic assistance or compensation and some may even decide to promise but later renege. What is involved in this trade-off between reduction of greenhouse gases on the one hand and economic development or growth on the other hand? This article portrays this connection by means of figures on key countries. The closer the link between GDP and emissions is, the more painful or costly will the transition to a reduction of emissions be.

\subsection{Greenhouse Gases}

Greenhouse gases (GHG) contribute to the so-called greenhouse effect, which boils down to continuous overall warming of the Planet Earth. Atmospheric gases trap electromagnetic radiation from the sun that would otherwise have been reflected back out into space. These greenhouse gases include: methane, 
nitrous oxide, carbon dioxide, hydro fluorocarbons (HFCs), per fluorocarbons (PFCs), and sulphur hexafluoride (SF6). But these gases make up only a small fraction of the gases of the atmosphere. Figure 1 shows the actual situation with these tiny GHG:s.

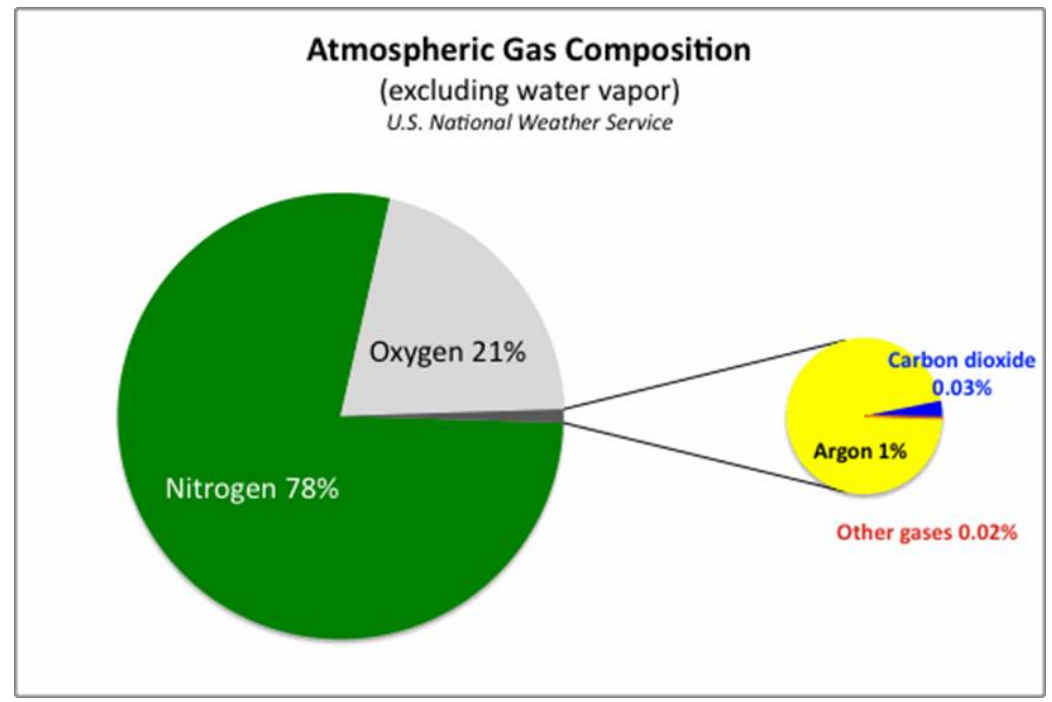

Figure 1. The Atmosphere Gas Elements

The composition of the atmosphere comprises basically nitrogen and oxygen with merely 0.05 per cent carbon dioxide and other GHG:s. Can these tiny particles really bring future disaster to mankind? Answer: YES!

20 per cent of the greenhouse effect is attributed directly to carbon dioxide with 5 per cent to the remaining 6 greenhouse gases. 75 per cent of the greenhouse effect is thought to be due to naturally-occurring water vapour and clouds. Some greenhouse gases are produced in natural processes, like forest fires, animal manure and respiration, or volcanic eruptions. However, the majority of new greenhouse gases are produced from industrial processes with huge energy consumption as well as energy production.

\subsection{Energy Emissions}

Fighting global warming involves reflecting upon several measures, as with the CAP21 conference in Paris, including:

- Slowing population growth,

- Changing agricultural production modes,

- Water recycling and waste treatment,

- Ocean protection,

- Changes in energy consumption: "decarbonisation",

- $\quad$ Stopping deforestation and protecting rain forest. 
Although energy is far from the only source of greenhouse gases, it is the single largest one. Energy use crops up in all forms of activities most often with an economic element: industry, transportation-land, sea, air, housing and commerce as well as food production and agriculture (Figure 2).

\section{World Energy Consumption by Sector, 2012 (EIA Data)}

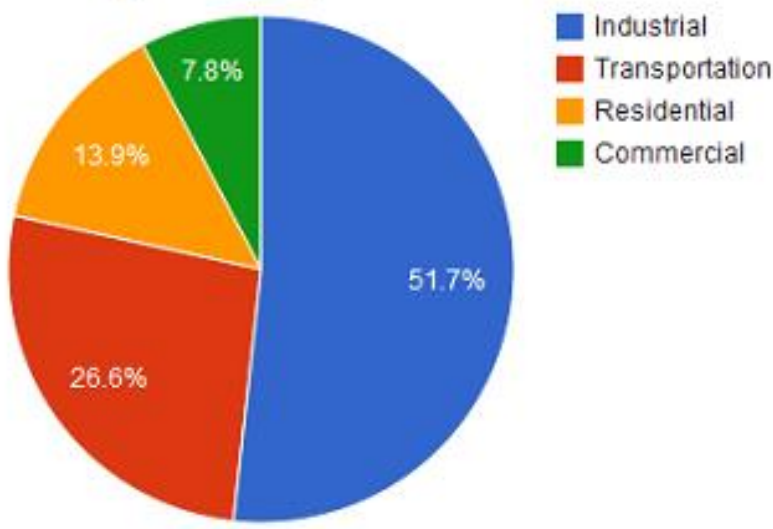

Figure 2. World Energy

The energy question concerns how all these vital activities in our economic and social systems like the family are to be furnished from a few sources of energy.

Globally speaking, around 80 per cent of the energy consumed daily is derived from the burning of fossil fuels. How fast can this be changed and what could be the economic costs of decarbonisation? Countries can attempt to meet their obligations in the COP21 Agreement by decarbonisation, lower economic growth or more energy efficiency. New technology and innovations will be crucial, not only in small scale endeavours but used massively. We wish to find out below is how countries vary in terms of their energy consumption.

\subsection{Decarbonisation and Economic Development}

Economist Sachs at the policy tank the Earth Institute has launched a coherent call for the world to move towards sustainable development, based on decarbonisation of the energy systems of countries (Retrieved from http://www.jeffsachs.org/2015/08/sustainable-development-for-humanitys-future/). He has correctly emphasized the close link between economic development or growth and the massive use of fossil fuels as energy sources during the last 20 years, resulting in the enormous expansion of GHG emissions along with phenomenal increase in GDP output. Decarbonisation would halt climate change, but what energy sources are to be used? Sachs says that GDP will fall, but few governments are willing to take on this cost of negative economic growth for the achievement of COP21 goals.

The Figure 3 displays this link. 


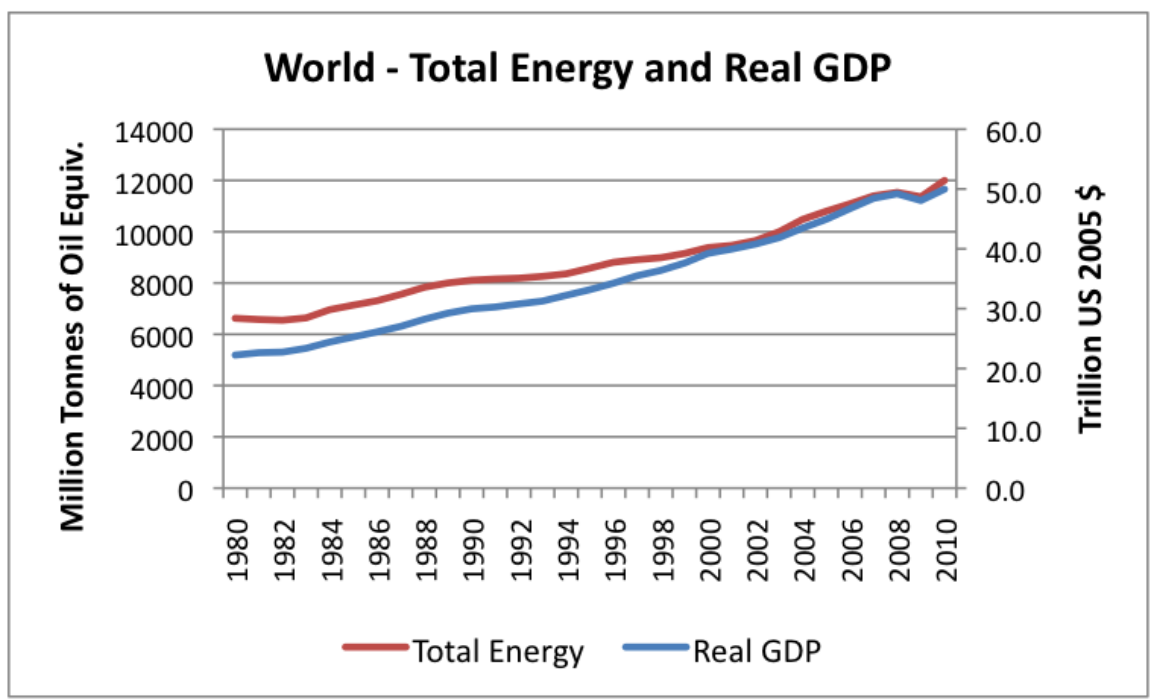

Figure 3. Growth in World Energy Consumption (Based on BP Energy Outlook Data) and Growth in World Real GDP

However, given this close link between GDP and energy consumption, how can the countries of the world achieve decarbonisation without hampering economic development or growth? What is the country link between GDP and GHG emissions? It depends upon the nation in question!

\subsection{Very Strong Link: GDP-GHG}

One may find that the emissions of GHG:s follows economic development closely in many countries. The basic explanation is population growth and GDP growth-more people and higher life style demands. Take the case of China, whose emissions are the largest in the world, totally speaking (Figure 4).

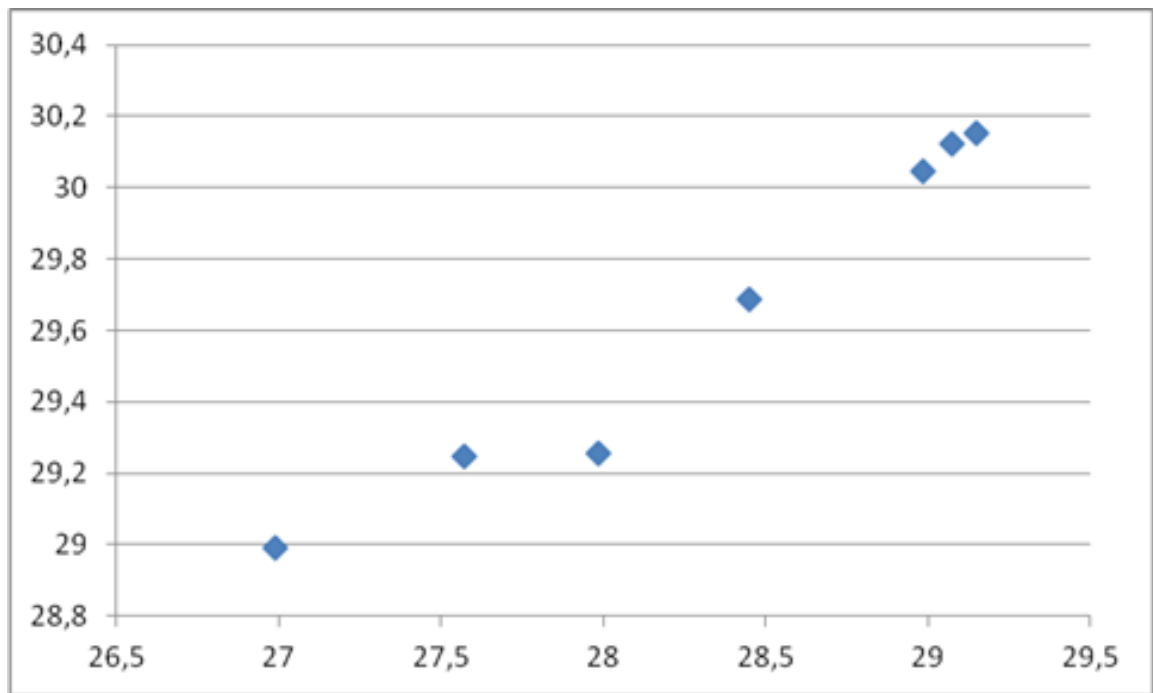

Figure 4. China: LN (GHG/Kg CO2 eq and LN (GDP/Constant Value 2005 USD) Note: $\mathrm{GHG}=\mathrm{y}$-axis, GDP $=\mathrm{x}$-axis. 
The sharp increase in GHG:s in China reflects not only the immensely rapid industrialization and urbanization of the last 30 years, but also its problematic energy mix (Figure 5).

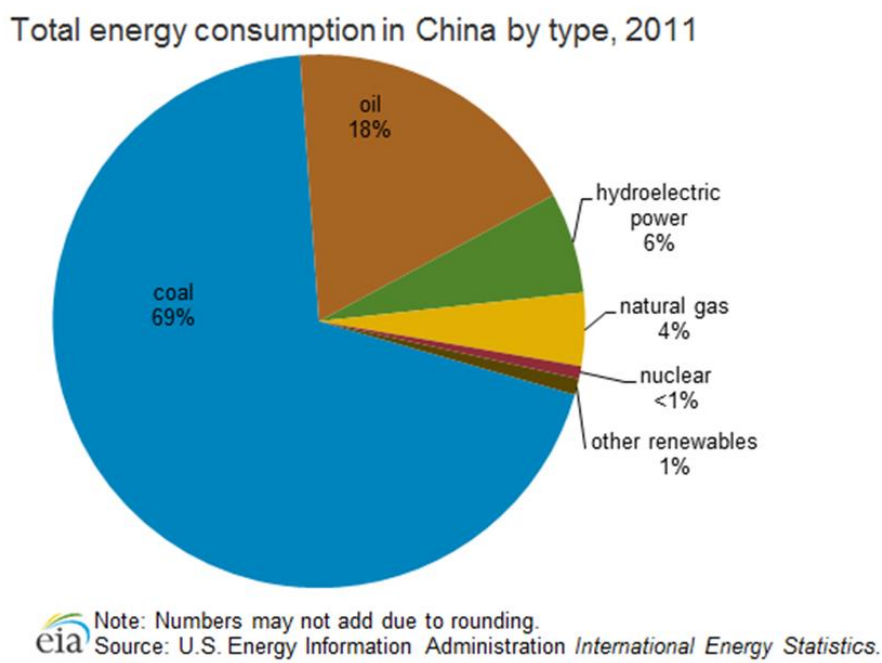

Figure 5. China

Almost 70 per cent of the energy consumption comes from the burning of coal with an additional 20 per cent from other fossil fuels. The role of nuclear, hydro and other renewable energy sources is very small indeed. This makes China very vulnerable to demands for cutting GHG emissions: other energy sources or massive installation of highly improved filters?

It should be pointed out that several small countries have much higher emissions per capita than China. This raises the enormously difficult problematic of fair cuts of emissions. Should the largest polluters per capita cut most or the biggest aggregate polluters? At COP21 this issue was resolved by the creation of a super fund to assist energy transition and environment protection in developing counties, as proposed by economist Stern (2007).

India will certainly appeal to the same problematic, namely per capita or aggregate emissions. The country is even more negative than China to cut GHG emissions, as it is in an earlier stage of industrialization and urbanization. Figure 6 shows the close connection between emissions and GDP for this giant nation. 


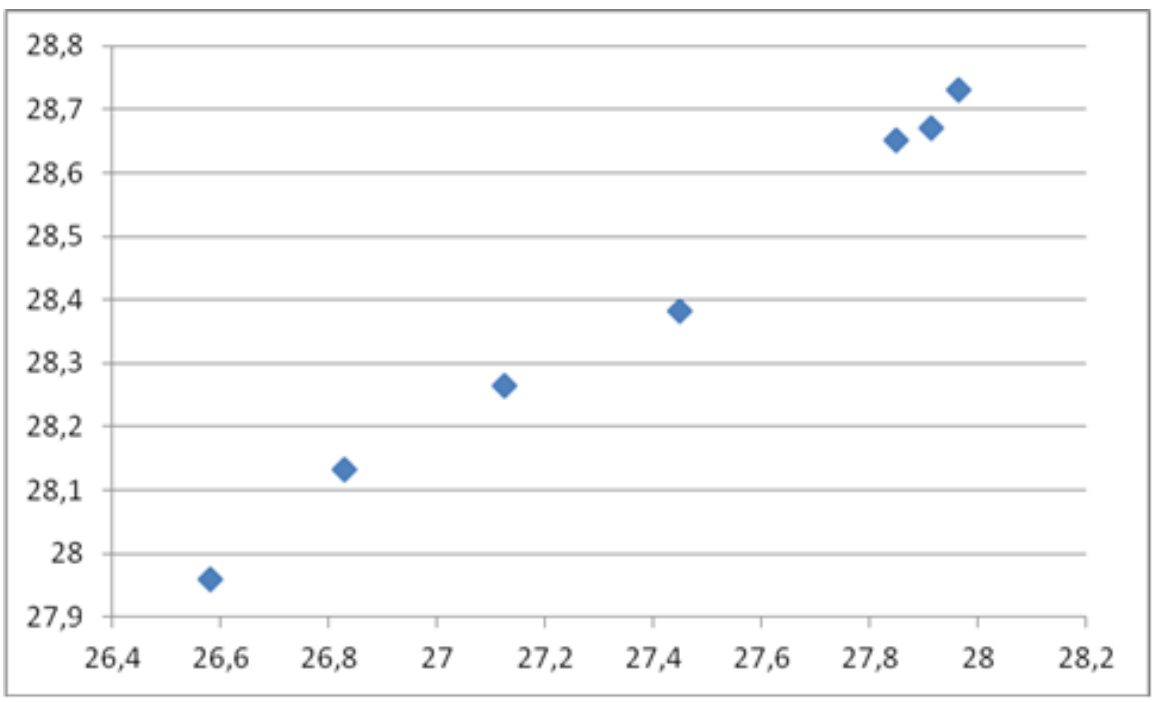

Figure 6. India: LN (GHG/Kg CO2 eq and LN (GDP/Constant Value 2005 USD)

Note: $\mathrm{GHG}=\mathrm{y}$-axis, $\mathrm{GDP}=\mathrm{x}$-axis.

India needs cheap energy for its industries, transportation and heating (Figure 7) as well as electrification. From where will it come? India has water power and nuclear energy, but relies most upon coal, oil and gas as power source. It has strong ambitions for the future expansion of energy, but how is it to be generated, the world asks. India actually has one of smallest numbers for energy per capita, although it produces much energy totally. Figure 8 shows its energy mix where renewables play a bigger role than in China.

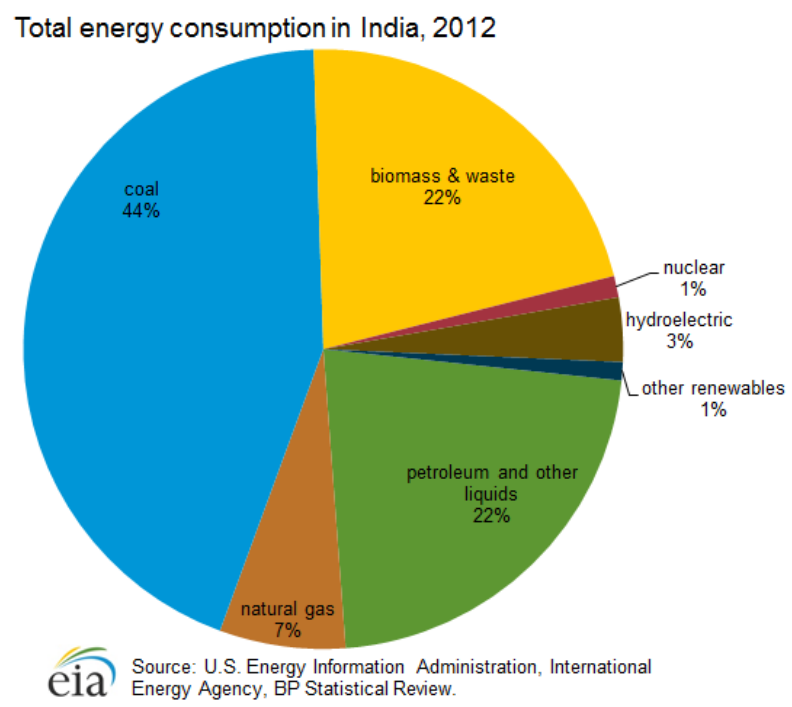

Figure 7. India 
India needs especially electricity, as 300 million inhabitants lack access to it. The country is heavily dependent upon fossil fuels (70 per cent), although to a less extent than China. Electricity can be generated by hydro power and nuclear power, both of which India employs. Yet, global warming reduces the capacity of hydro power and nuclear power meets with political resistance. Interestingly, India uses much biomass and waste for electricity production, which does not always reduce GHG emissions. India's energy policy will be closely watched by other governments and NGO:s after 2018.

One may find a close link between GDP and emissions also in countries with an extremely advanced economy. See Figure 8 for South Korea.

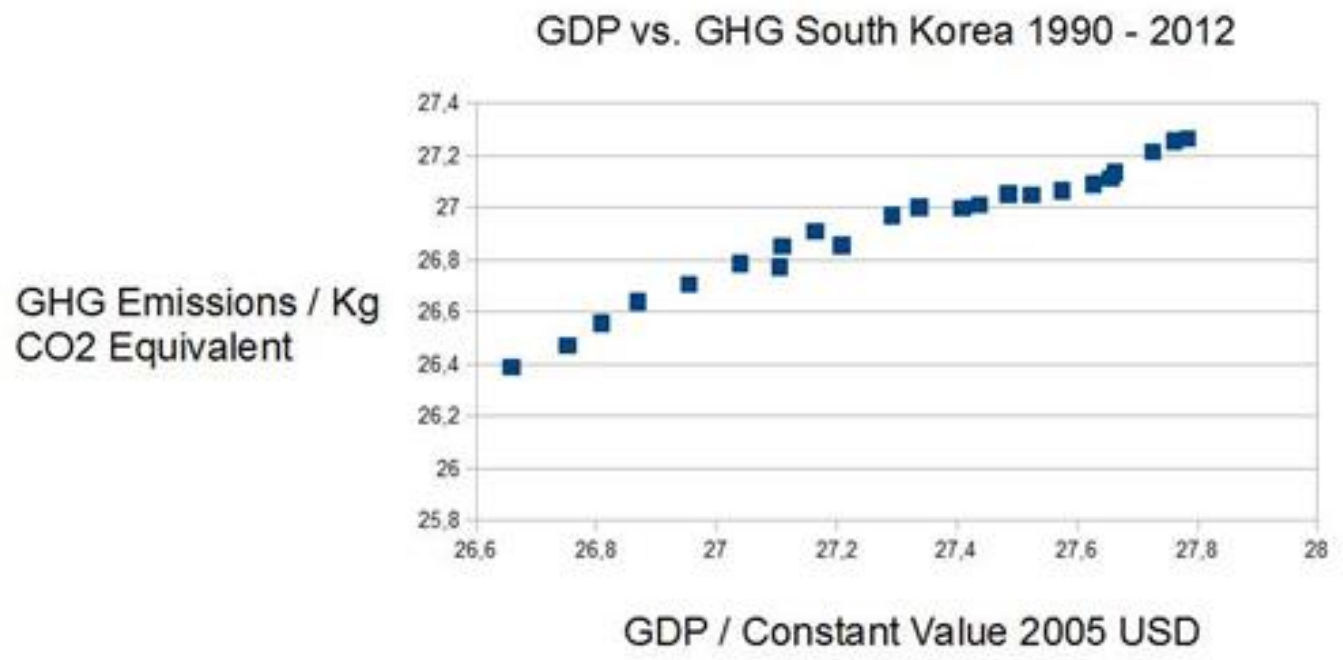

Figure 8. South Korea: LN (GHG/Kg CO2 eq and LN (GDP/Constant Value 2005 USD)

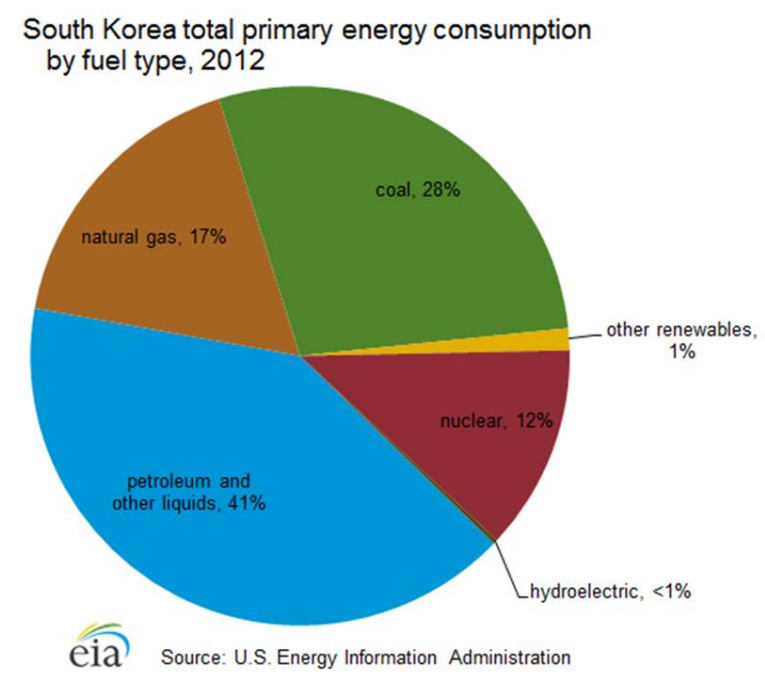

Figure 9. South Korea 
Lacking much hydro power, South Korea has turned to fossil fuels for energy purposes, almost up to 90 per cent (Figure 9). It differs from China only in the reliance upon nuclear power, where the country is a world leader in plant constructions. Reducing its hefty GHG emissions, South Korea will have to rely more upon renewable energy sources, as well as reducing coal and oil for imported gas or LNGs.

Specific Energy, Energy Density \& CO2
\begin{tabular}{|lcclc|}
\hline Fuel & $\begin{array}{c}\text { Specific Energy } \\
\text { kj/g }\end{array}$ & $\begin{array}{c}\text { Density } \\
\text { KWH/gal }\end{array}$ & $\begin{array}{l}\text { Chemical } \\
\text { Formula }\end{array}$ & Ibs CO2/gal \\
\hline Propane & 50.4 & 26.8 & C3H8 & 13 \\
Ethanol & 29.7 & 24.7 & C2H5OH & 13 \\
Gasoline & 46.5 & 36.6 & C7H16 & 20 \\
Diesel & 45.8 & 40.6 & C12H26 & 22 \\
Biodiesel & 39.6 & 35.0 & C18H3202 & 19 \\
Methane & 55.8 & 27.0 & CH4 & 3 \\
Oil & 47.9 & 40.5 & C14H30 & 20 \\
Wood & 14.9 & 11.3 & approx weight & 9 \\
Coal & 30.2 & 22.9 & approx weight & 19 \\
Hydrogen & 141.9 & 10.1 & H2 & 0 \\
\hline
\end{tabular}

Source: DOE, Stanford University, College of the Desert, \& Green Econometrics research

Figure 10. Types of Energy and Emissions

The above three countries are giant polluters in terms of GHGs. China and South Korea uses mainly fossil fuels for energy consumption, whereas India also employs renewables and hydro power, lacking in the other two. Yet, the burning of renewables like biomass and waste for electricity generation also leads to GHG emissions. Only nuclear and hydro constitute emissions neutral energy (Figure 10).

Only hydrogen is carbon neutral, according to Figure 10. Ethanol and renewables like wood or biodiesel are not.

\subsection{Not So Strong Link: GHG-GDP}

The picture of a very close link between GDP and emission of GHG:s that is to be found with the three giants in Asia does not necessarily hold for all countries. Let us look at a few countries where this link is weaker, starting with Canada that has halted the expansion of GHG:s (Figure 11). 
GDP vs. GHG 1990 - 2012 for Canada

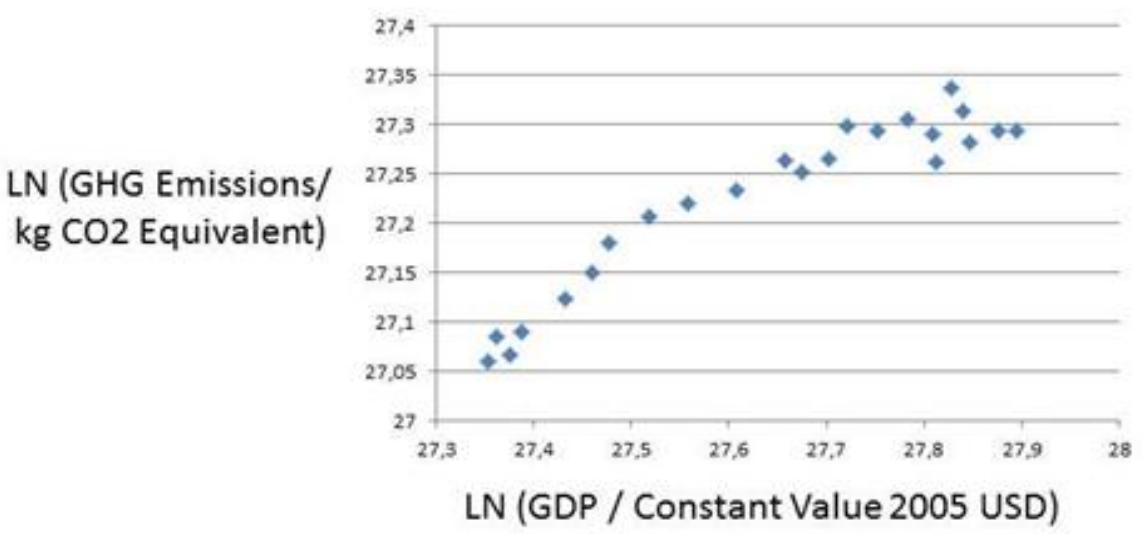

Figure 11. Canada: LN (GHG/Kg CO2 eq and LN (GDP/Constant Value 2005 USD)

Although Canada is a major emitter of GHG:s as well as one of the world's largest fossil fuel producer-oil sands, it had managed to stem the increase in emissions for the most recent years, i.e., halting the augmentation. Figure 12 may be invoked to explain this, showing a very mixed energy consumption pattern.

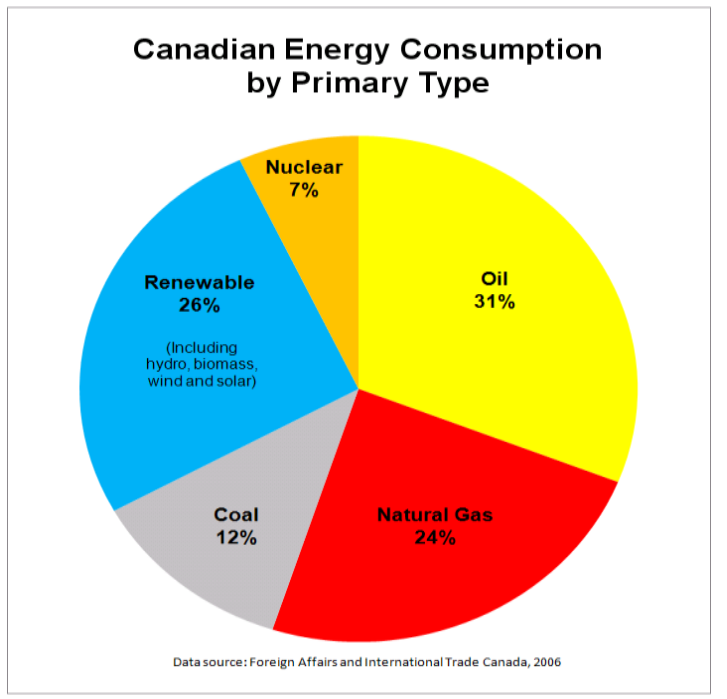

Figure 12. Canada

Canada has a strong advantage compared with for instance China and India in that it has access to lots of hydro power and natural gas. The burning of coal is as low as 12 per cent, but oil still makes up almost a third of energy consumption.

Let us look at the ethanol country par preference: Brazil. Figure 13 shows a considerable drop in total emissions, but it is followed by huge increases that tend to flatten out. 


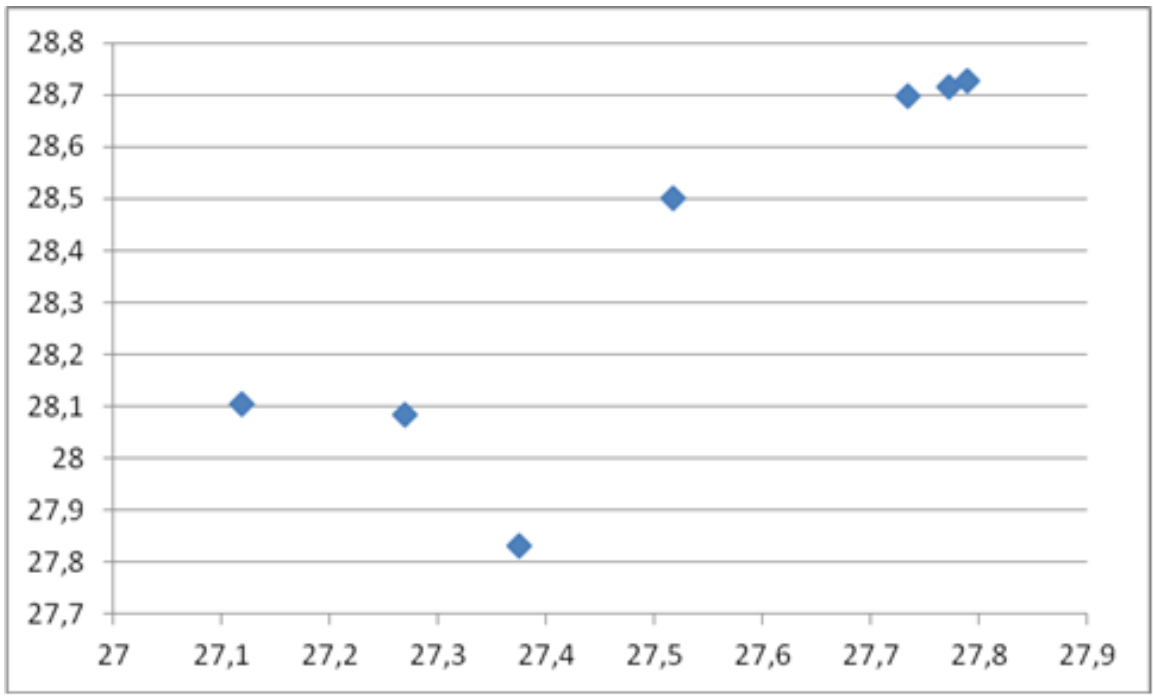

Figure 13. Brazil: LN (GHG/Kg CO2 eq and LN (GDP/Constant Value 2005 USD) Note: $\mathrm{GHG}=\mathrm{y}$-axis, $\mathrm{GDP}=\mathrm{x}$-axis.

Brazil employs the most biomass in the world, but the emissions stay at a high level, which is a reminder that renewables may also have GHGne advantage for Brazil is the large component of hydro power, but the overall picture for the largest Latin American country is not wholly promising when it comes to reduction of emissions. Global warming reduces the potential of hydro power, and Brazil has very little nuclear power (Figure 14).

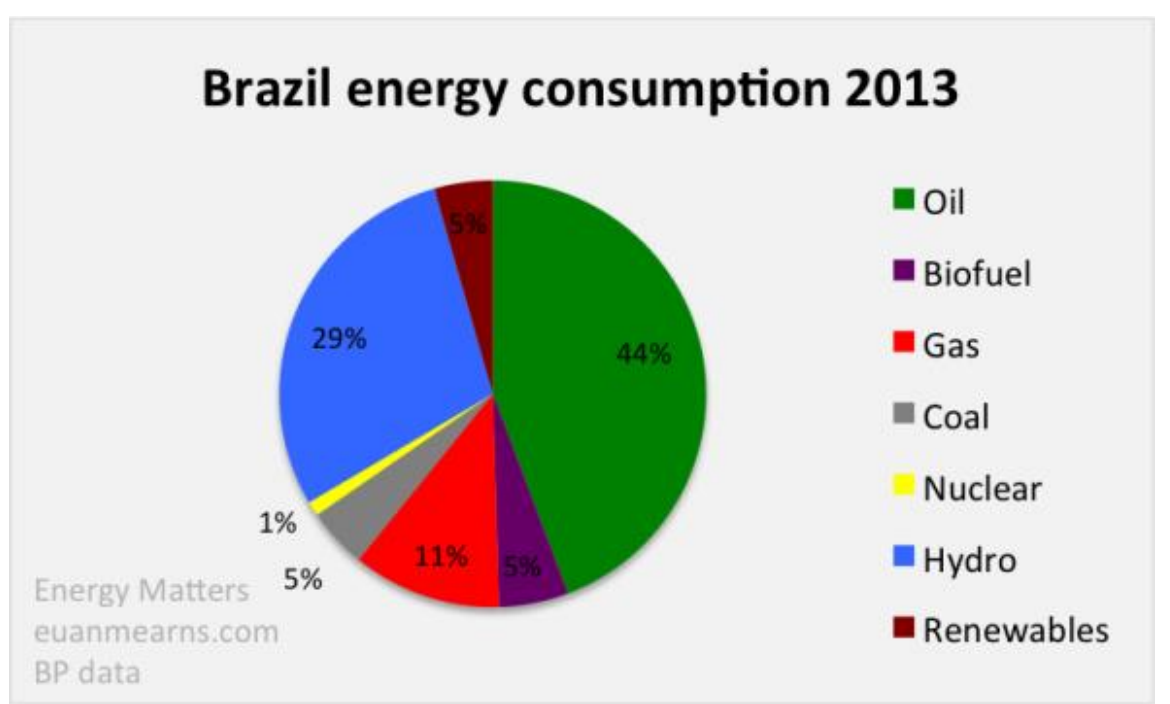

Figure 14. Brazil 


\subsection{Weak Link: GHG-GDP}

For most countries hold that their emission of GHG:s increases, as well as augments with the GDP. However, there are a few notable exceptions of decreases that are worth mentioning. We start with the US (Figure 15).

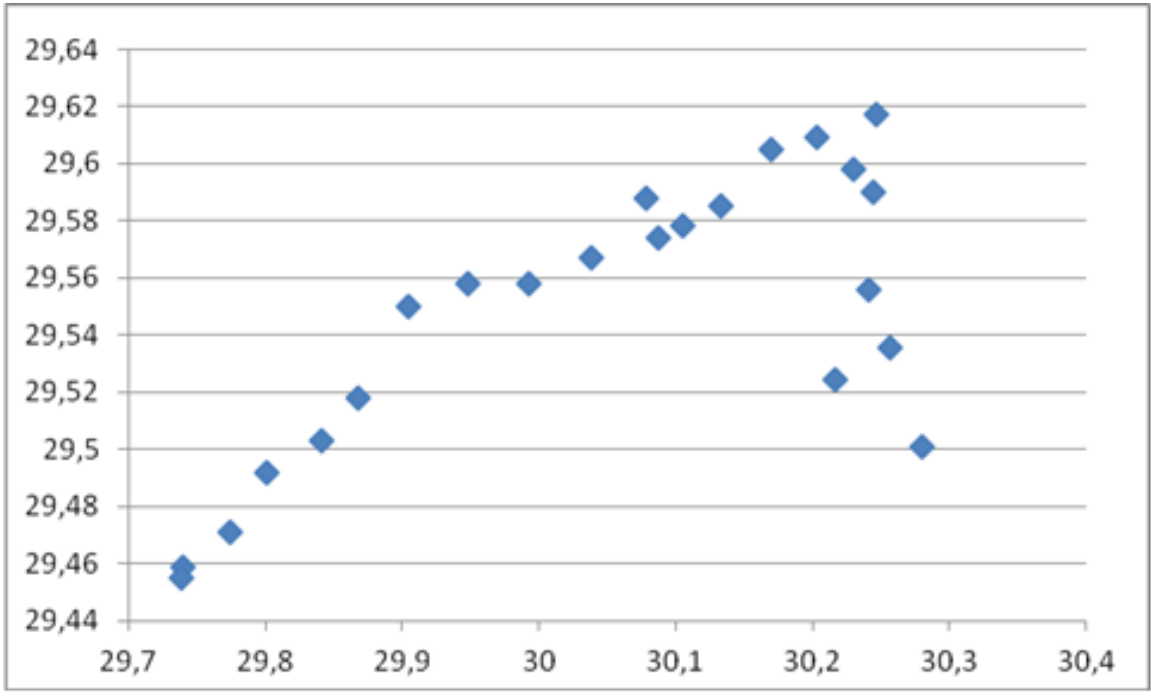

Figure 15. USA: LN (GHG/Kg CO2 eq and LN (GDP/Constant Value 2005 USD)

Note: $\mathrm{GHG}=\mathrm{y}$-axis, $\mathrm{GDP}=\mathrm{x}$-axis.

Recently, the level of GHG emission has been reduced significantly in the US. It reflects no doubt the economic crisis that began 2007, but the US remains the second largest polluter in the world, reflecting that it cannot draw upon a mixed bag of energies (Figure 16). Per capita GHG:s is of course very high for the USA. As the economy now starts to accelerate, emissions are bound to go up again.

\section{U.S. Energy Consumption by Energy Source, 2011}

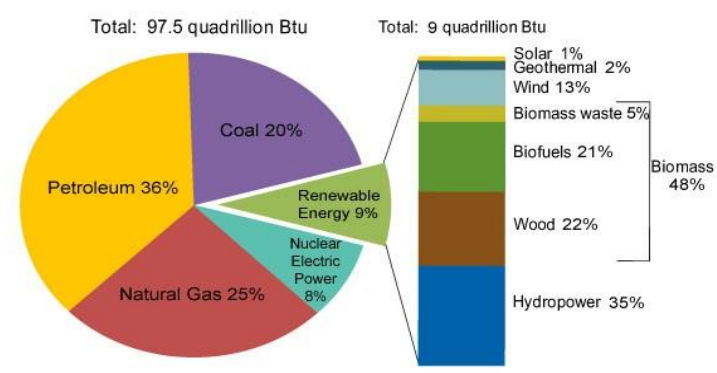

Source: U.S. Energy Information Administration, Monthly Energy Review, Table 10.1 (March 2012), preliminary 2011 data.

Figure 16. USA 
The US is heavily dependent upon fossil fuels, or some 89 per cent comes there from. What is changing is the more and more of energy is produced within the US and no longer imported from outside- the shake oil and gas revolution. Further reduction of GHG:s will meet with firm resistance from the Republican House of Congress, which may oppose the COP21 Agreement. The advent of shale oil and gas has changed the entire energy markets, lowering the price of oil most substantially. This implies not only that there will be no Hubbert peak oil for the world, but also that switching to renewable energy source will be extremely expensive, relatively speaking.

Another interesting country is the largest EU economy, namely Germany. Figure 17 shows a marked decrease in GHG emissions.

GDPVs. GHG emissions

Germany 1990 - 2011

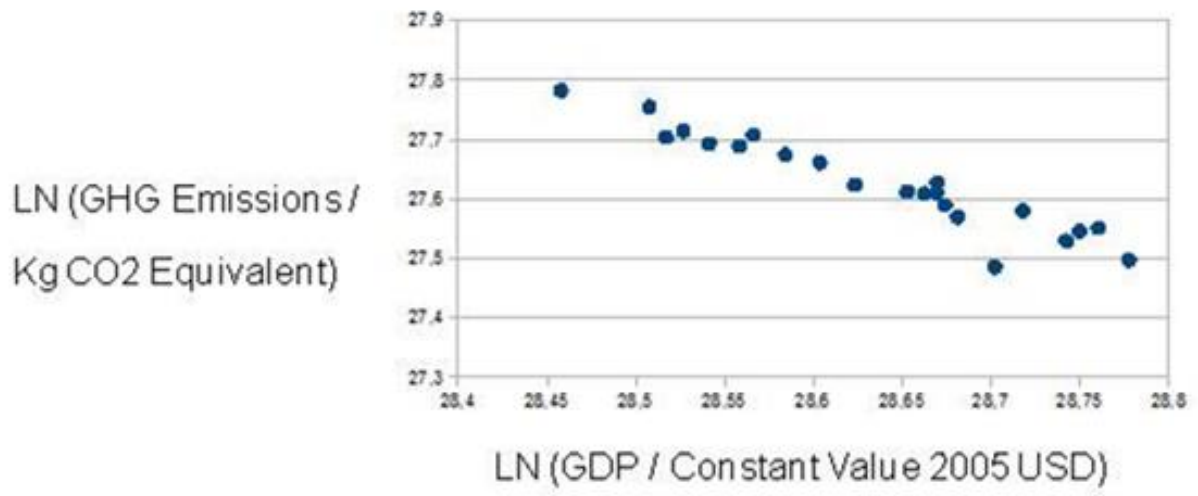

Figure 17. Germany: LN (GHG/Kg CO2 eq and LN (GDP/Constant Value 2005 USD)

The German data shows a consistent decreasing trend, which is not to be found with many countries, if at all. How come this German exceptionalism? Germany needs massive amounts of energy, but it decided to phase out nuclear power. Can really the domestic employment of renewables satisfy this gigantic demand (Figure 18)? 


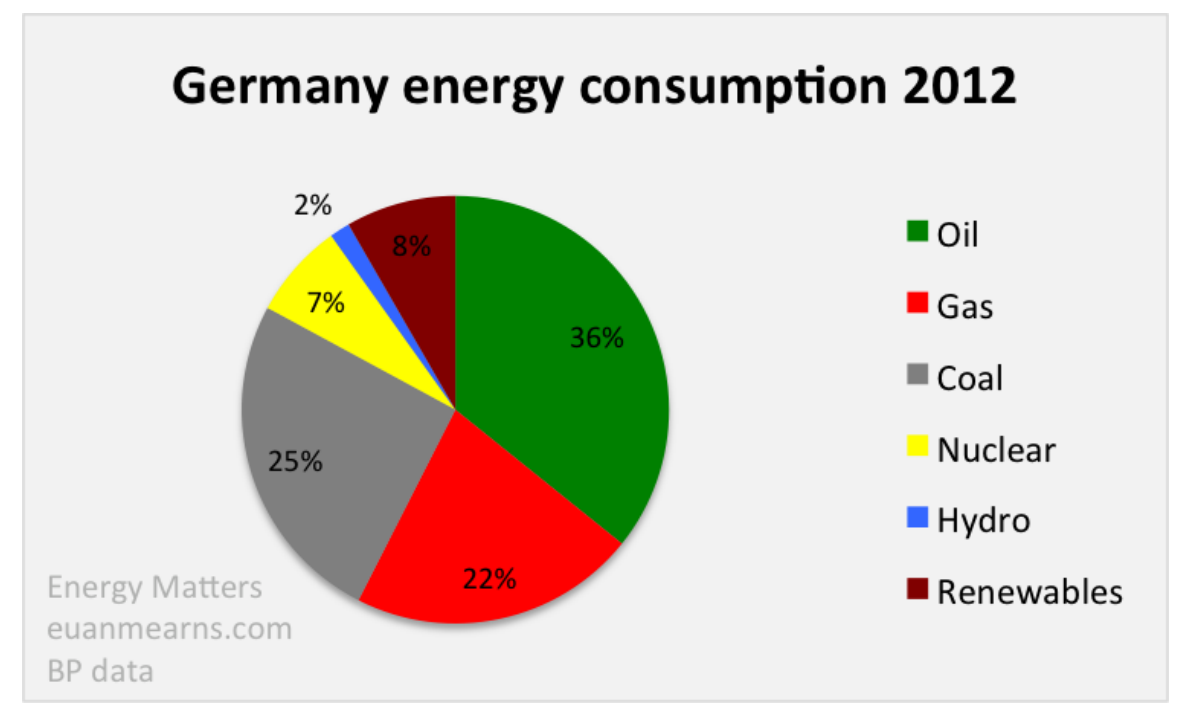

Figure 18. Germany

It is true that nuclear power and renewables has made it possible for Germany to decrease its GHG:s, but the country is still dependent upon fossil fuels, especially coal and oil. What will happen with the nuclear power stations are phased out in 2022 is that most likely the GHG emissions will start going up again. To replace nuclear power with solar and wind power will be difficult to say the least. Already, Germany uses more coal from Columbia and gas from Russia.

\subsection{The Green States}

Some countries applaud themselves for a positive energy policy, i.e., a policy that leads to decreases in emissions. But is it really true? Look first at Singapore in Figure 19.

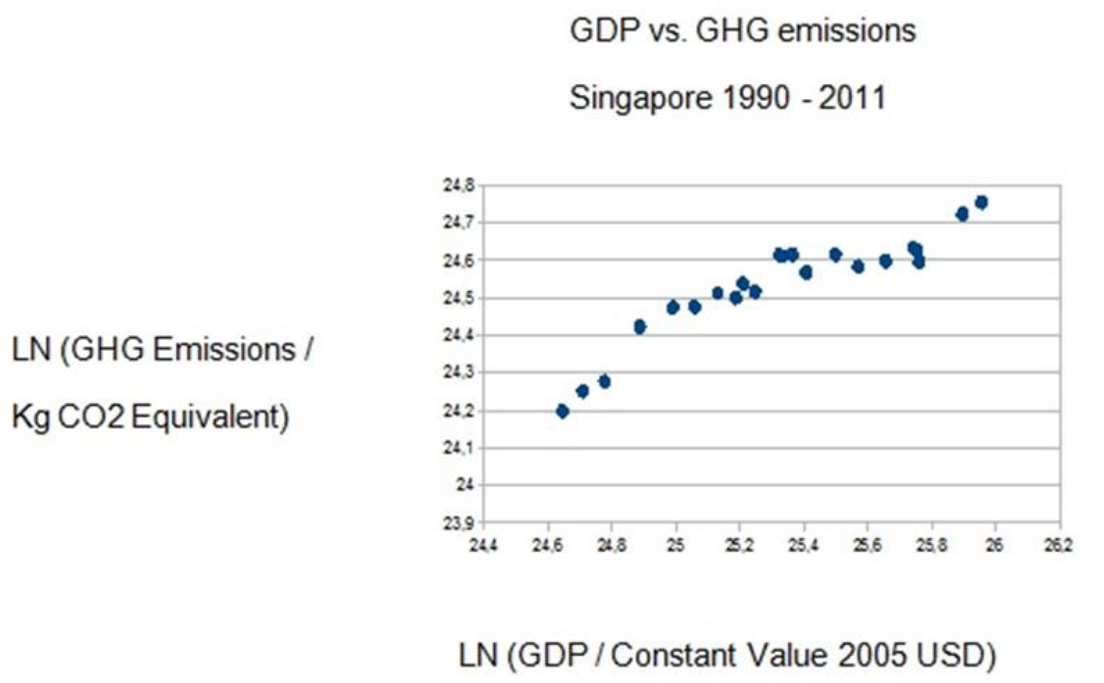

Figure 19. Singapore: LN (GHG/Kg CO2 eq and LN (GDP/Constant Value 2005 USD) 
Despite its official statements about being a GREEN city, emissions have been going up steadily in Singapore. The GHG:s is very high if related to per capita. Its energy mix is only oil and natural gas, imported from abroad (Figure 20). Singapore needs lots of electricity to bolster its advanced life style (air conditioning, total waste water cleaning, etc.).

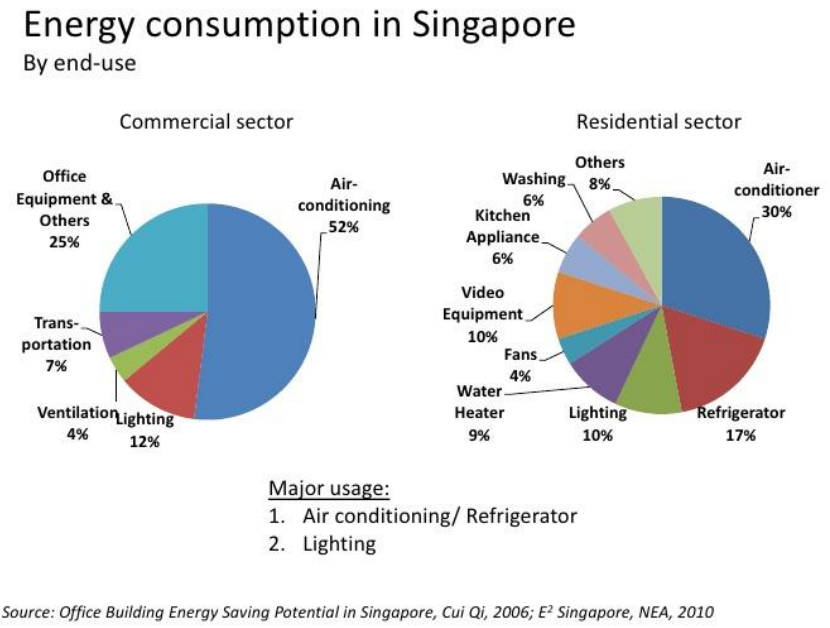

Figure 20. Singapore

Why would this island state need too much energy, resulting in such an amount of emission of GHG:s?

Reply: the need for fossil fuels to generate electricity and make transportation possible. Singapore has a hot climate and handles that with a complete use of air conditioners all over the place. It is also a huge hub for shipping and air travel. It is impossible to generate so much electricity without emissions when using fossils fuels. Singapore has a large oil refinery.

Consider now another GREEN state, the United Arab Emirates (Figure 21). 


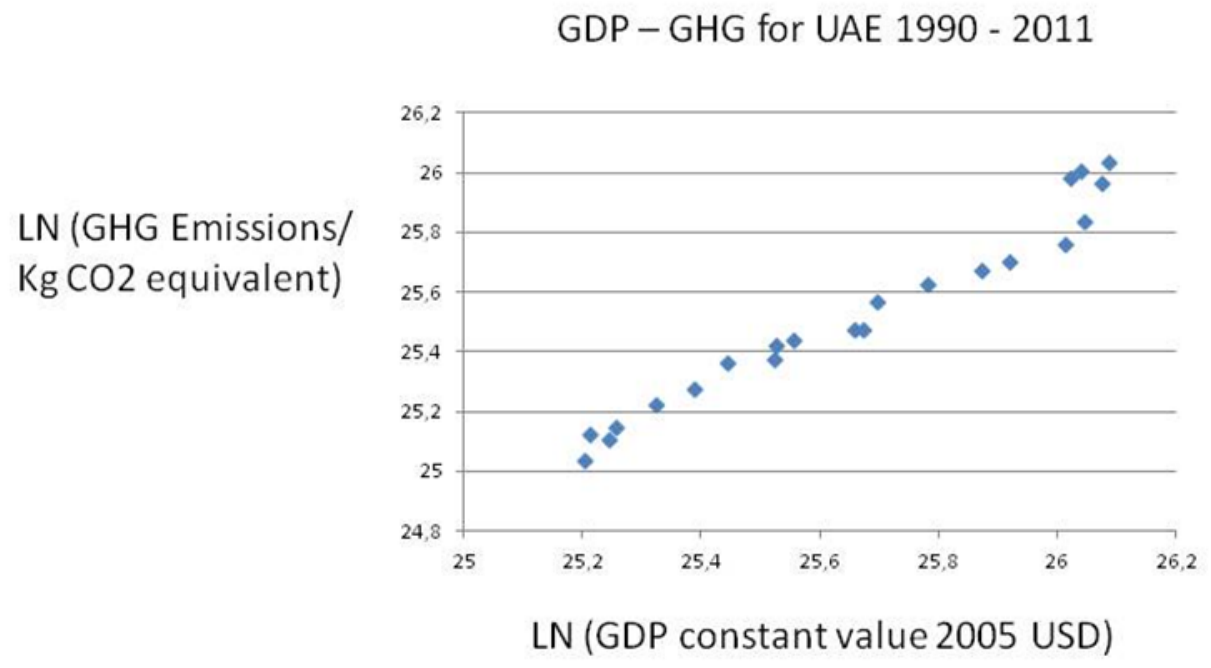

Figure 21. United Arab Emirates: LN (GHG/Kg CO2 eq and LN (GDP/Constant Value 2005 USD)

The UAE have increased their emission of GHG:s sharply in relation the positive economic development of these emirates. They rely upon the fossil fuels of Abu Dhabi with immense oil resources. Like other Gulf States, the UAE boosts with building entirely GREEN sites, with energy from solar power and almost no waste. But it is based upon their enormous consumption of electricity generated out of burning oil and gas (Figure 22). The Gulf countries use lots of petrol, gas and electricity to uphold a stunningly high standard of living, which also results in extremely high levels of emissions per capita.

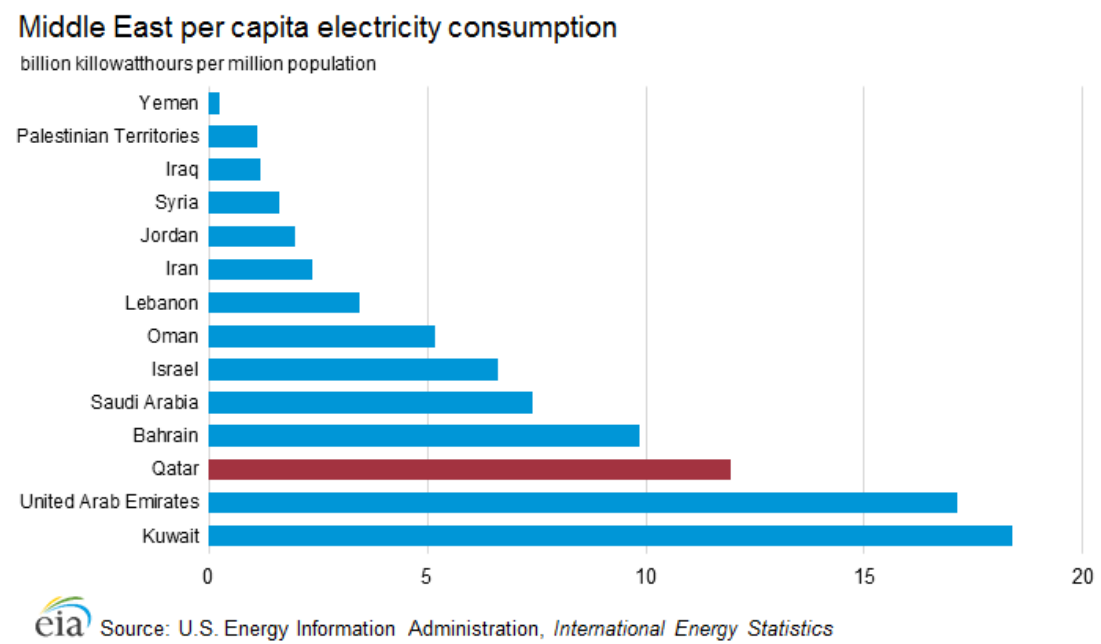

Figure 22. Electricity: Middle East 
The standard image is that of a close link between GDP and emissions, like for the so-called super rich GREEN states. What is the situation in a few major developmental countries?

\subsection{Developmental Countries: Strong Link GHG-GDP}

One may guess correctly that countries that try hard to "catch-up" will have increasing emissions. This was true of China and India. Let us look at three more examples, like e.g., giant Indonesia-the fourth largest emitter of GHG:s in the world.

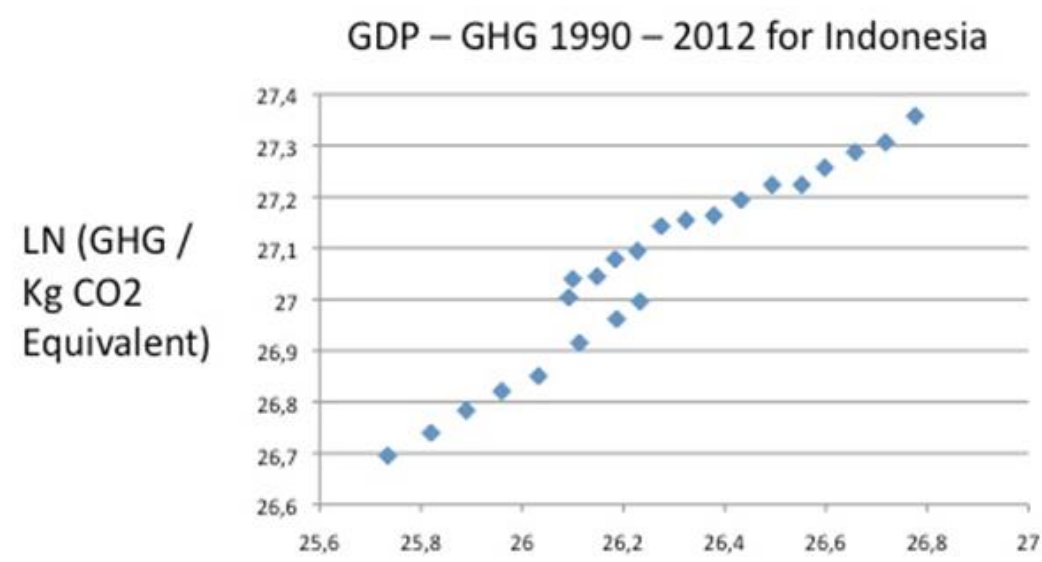

LN (GDP / Constant Value 2005 USD)

Figure 23. Indonesia: LN (GHG/Kg CO2 eq and LN (GDP/Constant Value 2005 USD)

Indonesia is a coming giant, both economically and sadly in terms of pollution. Figure 23 reminds of the upward trend for China and India. However, matters are even worse for Indonesia, as the burning of the rain forest on Kalimantan augments the GHG emissions very much. Figure 24 presents the energy mix for this huge country in terms of population and territory.

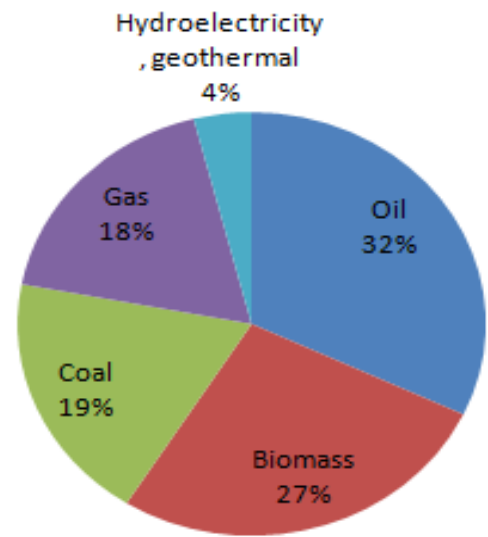

Distribution of Energy Consumption in Indonesia in 2009

Figure 24. Indonesia

Note: http://www.missrifka.com/energy-issue/recent-energy-status-in-indonesia.html 
Only 4 per cent comes from hydro power with 70 per cent from fossil fuels and the remaining 27 per cent from biomass, which alas also pollutes.

The same upward trend holds for another major developing country with huge population, namely Pakistan (Figure 25).

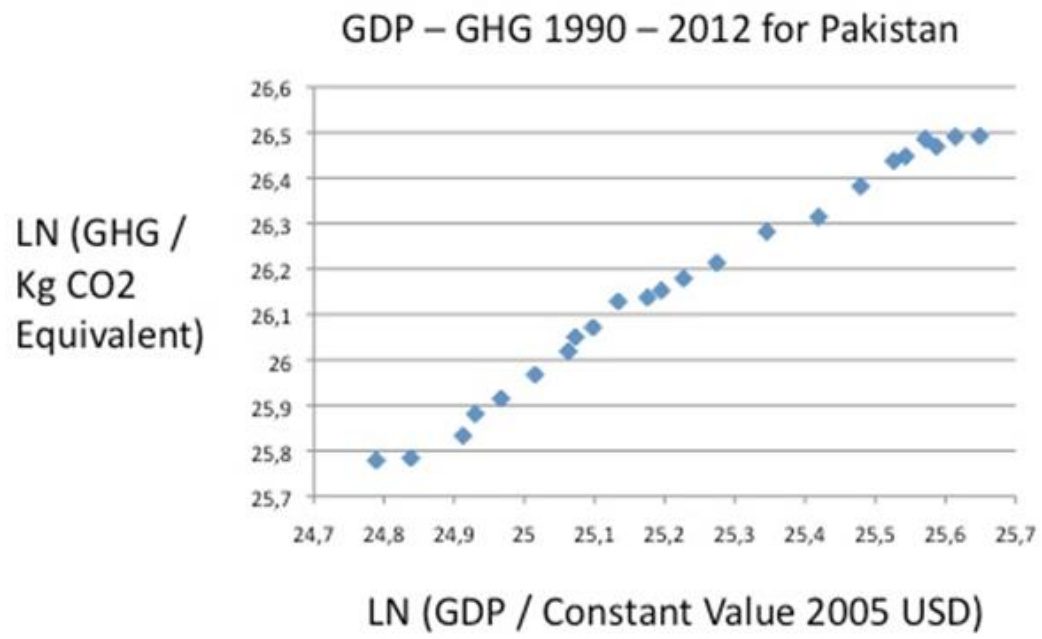

Figure 25. Pakistan: LN (GHG/Kg CO2 eq and LN (GDP/Constant Value 2005 USD)

The amount of GHG emissions is high for Pakistan, viewed as aggregate. Pakistan is mainly reliant upon fossil fuels (Figure 26).

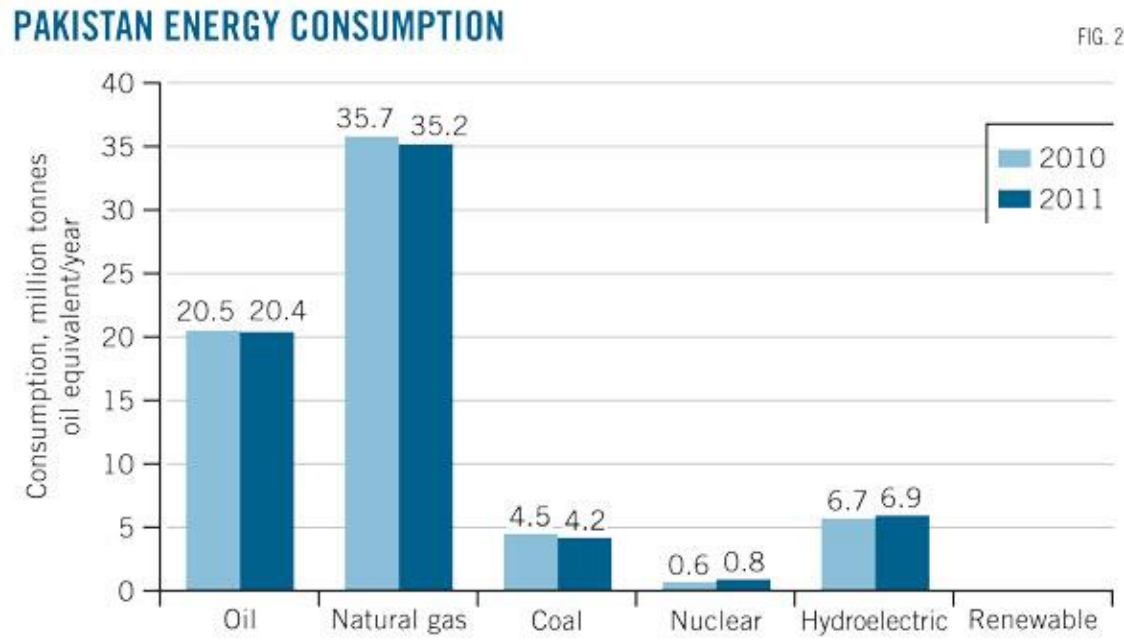

Source: BP Statistical Review of World Energy 2012

Figure 26. Pakistan 
But Pakistan employs a considerable portion of hydropower-13 per cent - and a minor portion of nuclear power. A clear advantage for Pakistan is its heavy reliance upon gas instead of coal as in Indida.Looking at South Africa in Figure 27, it is the same trend.

Emissions are high, because South Africa uses a lot of coal to generate electricity (Figure 31). Decarbonisation will be difficult and costly.

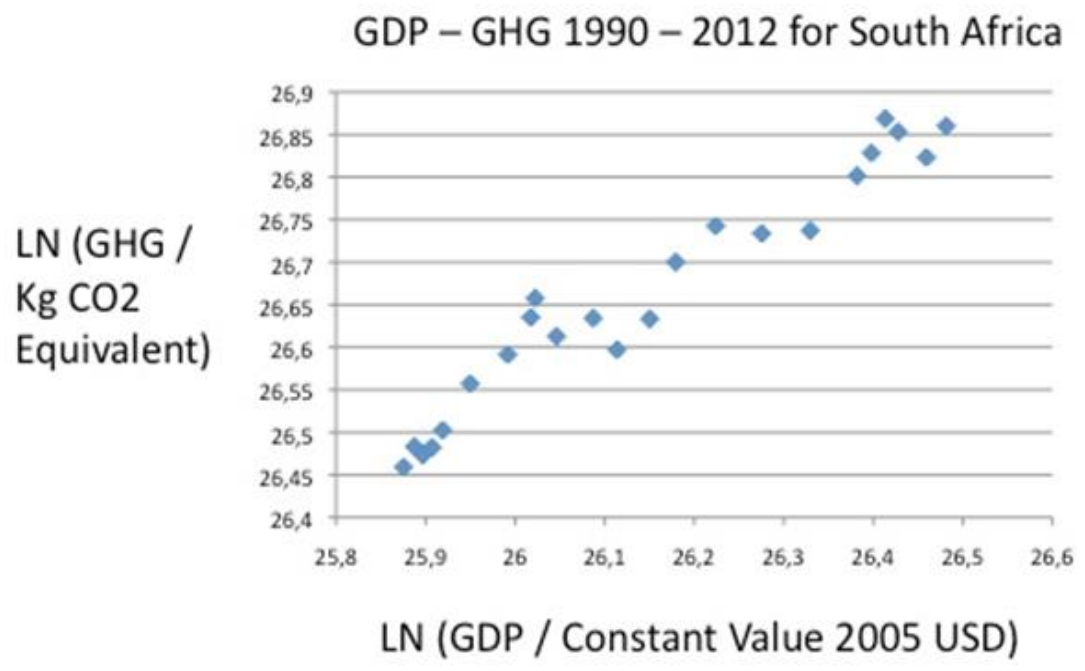

Figure 27. South Africa: LN (GHG/Kg CO2 eq and LN (GDP/Constant Value 2005 USD)

\section{Total primary energy consumption in South Africa, 2012}

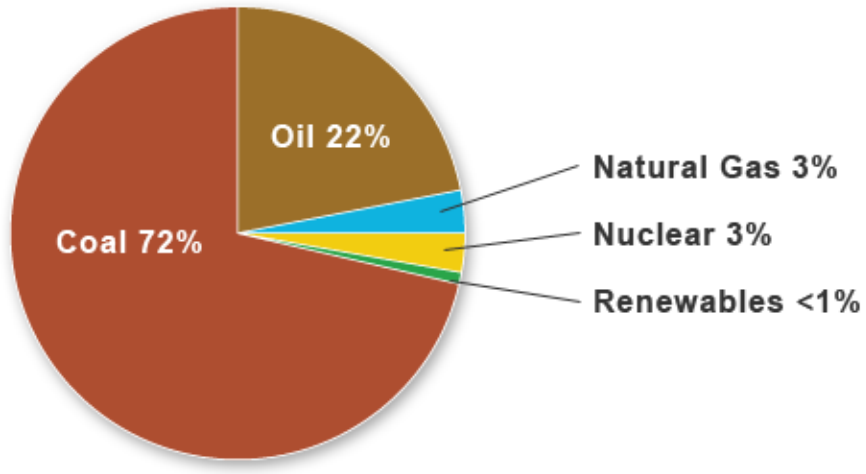

Source: BP Statistical Review of World Energy 2013

Figure 28. Energy Consumption in RSA

The reliance upon coal in this the next largest economy in Africa is stunningly high. 


\section{Summing Up: Sachs' Dilemma}

Returning to Sachs, one can only say that decarbonisation will be hard to come by, especially for countries with little hydro or nuclear power. When the requirements of sustainable development collide with conventional economic growth, something has to give. It is not likely that decarbonisation will trump economic development, at least not enough to avoid $+2.7,+4$ or +6 scenarios. He states: "Economic development, social inclusion, and environmental sustainability are the three tenets underpinning the forthcoming post-2015 development agenda, a once in a generation opportunity to put mankind on the path to a sustainable growth model".

The overwhelming number of countries in the world displays the upward trend for the emission of GHG:s. A few has managed to halt this progression, linked closely to economic development. But very few have embarked on a path of credible path of diminishing these emissions. The great developing countries are still heavily dependent upon fossil fuels. It is true that hydro power and nuclear power are employed in some countries, but a significant increase in these power sources cannot be expected. Wind and solar power are still in infancy. Biomass has been resorted to on a large scale in a few countries, but it is not carbon neutral.

When discussing the major objective of halting global warming at +2 , in order to avoid +4 or catastrophically +6 , a lot of measures are mentioned: carbon sequestration, trading schemes, carbon tax, support for new technologies and innovations, huge solar plants, massive wind power stations, wave energy, etc. But people forget that energy consumption is steadily going up, as global population increases and the quest for a high level life style is shared by more and more millions of people. What is gained on one side - energy efficiency, small scale solar and wind power-may simply be cancelled out by what is lost on the other side: dismantling of nuclear power stations, expansion of car transportation, bigger cars and SUV:s, more and more of air transportation, Beijing building largest airport in the world, etc.

\section{Conclusion}

A forceful move towards sustainable economic development would have to wait major innovations in energy consumption and they must prove economical too. But it may be too slow! The COP21 Agreement lacks completely information about how the major objective of +1.5 should be implemented, both technologically and legally - decentralised implementation. Strangely enough, the COP21 Treaty does not speak of filtering $\mathrm{CO} 2$ in all the coal plants!

A more effective strategy for promoting the COP21 objectives than Sachs' idea of a sustainable economy (utopian!) is to simply focus on where the worst pollution of the air comes from. Figure 29 below point clearly at coal. If these stylised projections in this Figure come true, then the COP21 goals will not be realised. 


\section{World energy-related $\mathrm{CO} 2$ emissions by fuel 1990 - 2035 (billion metric tons)}

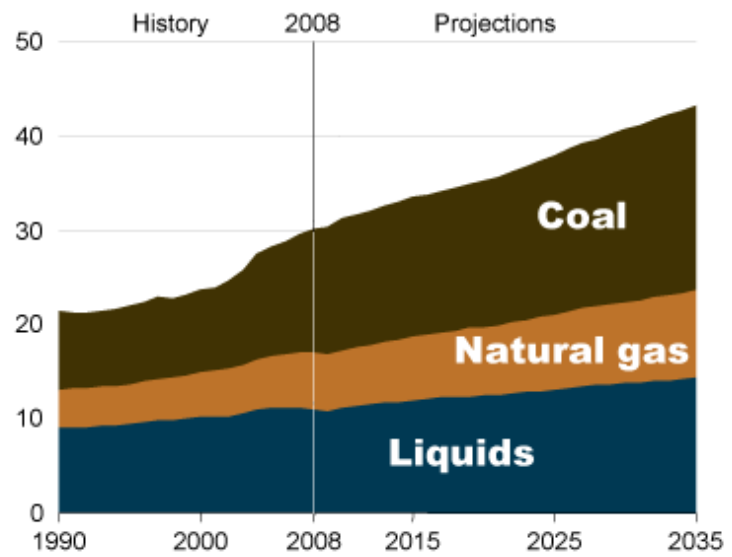

Figure 29. Role of Coal for $\mathrm{CO} 2$ Emission

Old coual pnats must be shut at once andno more ever constructed, especilly in thecountries above with a close link between GHG-GDP. Already built young coal plants must have strong and complete filters so remove ALL CO2, which is now feasible. This will cost, but there is now a super fund on the glbal level to pay from.

Figure 30 indicates that the renewable energy sources strategy is simply to slow. Planet Earth cannot wait until massive cheap solar energy is available and storage able. Moreover, nuclear power is contested and dismantled in many countries, sometimes replaced by: Coal? Replace all the coal fired power stations in 10 hugest emitters by gas or oil as well as renewables when really feasible and economical. Use complete filtration of the $\mathrm{CO} 2$ from all existing coal plants,

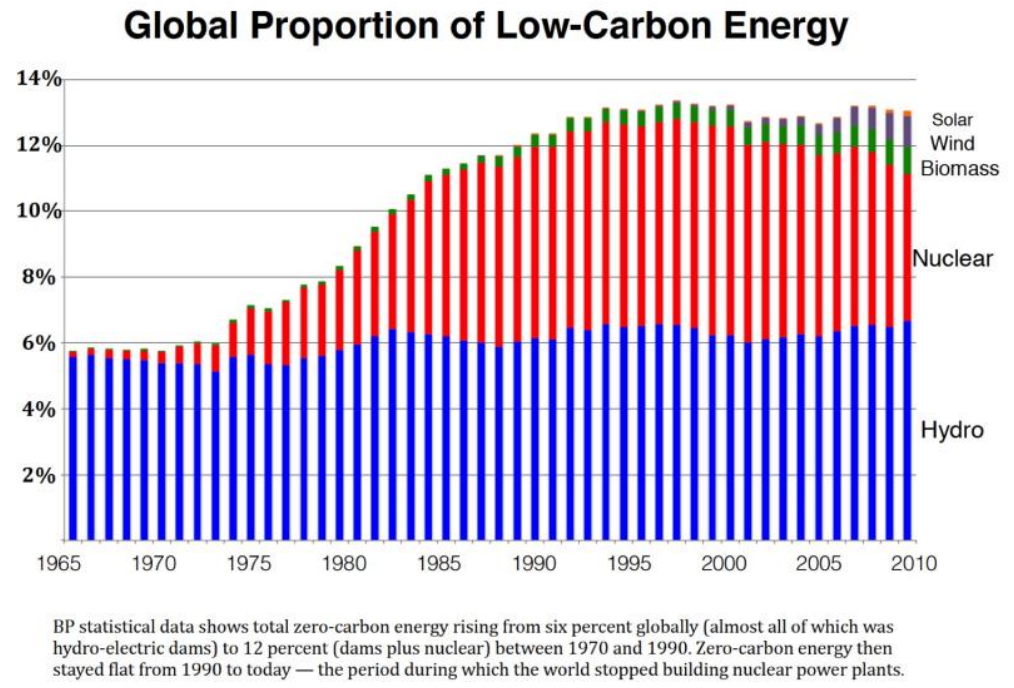

Figure 30. Trends for Types of Renewable Energy 
The truth today is that the harmful $\mathrm{CO} 2$ emissions increase per capita, even if a few countries have managed to halt this progression. Figure 31 provides enough evidence for deep pessimism about the implementation of COP21 objectives. To be able to reach the +2 goal, $\mathrm{Co} 2$ per capita must start decreasing considerable very soon. Both developing counties and developed countries remain at the same level of increase. The US decreases,, it is true, but from a phenomenally high level.

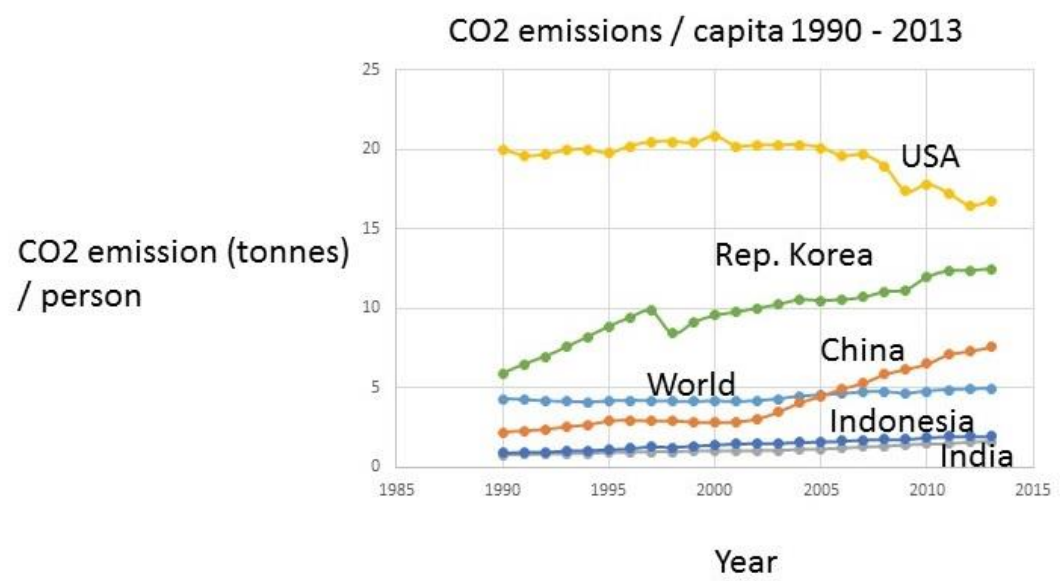

Figure 31. CO2 per Capita Emissions 1985-2013

Sources: EDGARv4.2, European Commission, Joint Research Centre (JRC)/PBL Netherlands Environmental Assessment Agency. Emission Database for Global Atmospheric Research (EDGAR), release version 4.2. http://edgar.jrc.ec.europe.eu, 2011,

United Nations Population Division. World Population Prospects,

United Nations Statistical Division. Population and Vital Statistics Report (various years),

Census reports and other statistical publications from national statistical offices,

Eurostat: Demographic Statistics,

Secretariat of the Pacific Community: Statistics and Demography Programme,

U.S. Census Bureau: International Database.

Can really global state coordination achieve a fundamental reversal of trends? The theory of collective actions predicts NO. Not only must coal be reduced sharply but also $\mathrm{CO} 2 \mathrm{~s}$ in transportation are far too high. And they increase.

\section{Sources}

GDP:

World Bank national accounts data-http://www.data.worldbank.org

OECD National Accounts data files

GHG: 
World Resources Institute CAIT Climate Data Explorer—http://www.cait.wri.org

EU Joint Research Centre Emission Database for Global Atmospheric

Research—http://www.edgar.jrc.ec.europa.eu/overview.php

UN Framework Convention on Climate Change-http://www.unfccc.int/ghg_data/ghg_data_ unfccc/time_series_annex_i/items/3814.php

Sachs, J. (August 10th, 2015). Sustainable Development for Humanity's Future. Retrieved from http://www.jeffsachs.org/2015/08/sustainable-development-for-humanitys-future/

International Energy Agency (IEA). Paris.

Energy Information Administration (EIA). Washington, DC.

\section{References}

Akpan, G. E. (2012). Electricity consumption. Carbon Emissions and Economic Growth in Nigeria, 2(4), 292-306.

Alam, M. J., Begum, I. A., Buysse, J., Rahman, S., \& Van Huylenbroeck, G. (2011). Dynamic modeling of causal relationship between energy consumption, $\mathrm{CO} 2$ emissions and economic growth in India. Renewable and Sustainable Energy Reviews, 15(6), 3243-3251.

Alkhathlan, K., \& Javid, M. (2013). Energy consumption, carbon emissions and economic growth in Saudi Arabia: An aggregate and disaggregate analysis. Energy Policy, 62(2013), 1525-1532.

Ang, J. B. (2008). Economic development, pollutant emissions and energy consumption Malaysia. Journal of Policy Modelling, 30(2), 271-278.

Arouri, M. E. H., Ben Youssef, A., M'henni, H., \& Rault, C. (2012). Energy consumption, economic growth and CO2 emissions in Middle East and North African countries. Energy Policy, 45(2012), 342-349.

Bloch, H., Rafiq, S., \& Salim, R. (2012). Coal consumption, CO2 emission and economic growth in China: Empirical evidence and policy responses. Energy Economics, 34(2), 518-528.

Halicioglu, F. (2009). An econometric study of $\mathrm{CO} 2$ emissions, energy consumption, income and foreign trade in Turkey. Energy Policy, 37(3), 1156-1164.

Jahangir, A. M., Ara, B. I., Buysse, J., \& Van Huylenbroeck, G. (2012). Energy consumption, carbon emissions and economic growth nexus in Bangladesh: Cointegration and dynamic causality analysis. Energy Policy, 45(2012), 217-225.

Kaygusuz, K. (2009). Energy and environmental issues relating to greenhouse gas emissions for sustainable development in Turkey. Renewable and Sustainable Energy Reviews, 13(1), 253-270.

Khan, M. A., Khan, M. Z., Zaman, K., Khan, M. M., \& Zahoor, H. (2013). Causal links between greenhouse gas emissions, economic growth and energy consumption in Pakistan: A fatal disorder of society. Renewable and Sustainable Energy Reviews, 25(2013), 166-176.

Kraft, J., \& Kraft, A. (1978). On the relationship between energy and GNP. Journal of Energy and Development, 3(2), 401-403. 
Lotfalipour, M. R., Falahi, M. A., \& Ashena, M. (2010). Economic growth, CO2 emissions, and fossil fuels consumption in Iran. Energy, 35(12), 5115-5120.

Mazmanian, D., \& Sabatier, P. (1989). Implementation and Public Policy (Second edition by University Press of America). Glencoe, Ill.: Scott Foresman \& Company.

Menyah, K., \& Wolde-Rufael, Y. (2010). Energy consumption, pollutant emissions and economic growth in South Africa. Energy Economics, 32(6), 1374-1382.

Ozturk, I., \& Acaravci, A. (2010). CO2 emissions, energy consumption and economic growth in Turkey. Renewable and Sustainable Energy Reviews, 14(9), 3220-3225.

PACJA (Pan African Climate Justice Alliance). (2009). The economic cost of climate change in Africa.

Pressman, J., \& Wildavsky, A. (1973). Implementation. Berkeley: University of Cal Press.

Pressman, J., \& Wildavsky, A. (1984). Implementation (3rd ed.). Berkeley: University of Cal Press.

Sabatier, P. (1988). An Advocacy Coalition Model of Policy Change and the Role of Policy-Oriented Learning Therein. Policy Sciences, 21, 129-168.

Soytas, U., Sari, R., \& Ewing, B. T. (2007). Energy consumption, income, and carbon Emissions in the United States. Ecological Economics, 62(3), 482-489.

Stern, N. (2007). The economics of climate change: The stern review. Cambridge: Cambridge University Press.

Wolde-Rufael, Y. (2006). Electricity consumption and economic growth: A time series experience for 17 African countries. Energy Policy, 34(10), 1106-1114.

Xepapadeas, A. (2005). Economic growth and the environment. In K. G. Ma“ler, \& J. R. Vincent (Eds.), Handbook of environmental economics (Vol. 3, pp. 1219-1271).

Zhang, X.-P., \& Cheng, X.-M. (2009). Energy consumption, carbon emissions, and economic growth in China. Ecological Economics, 68(10), 2706-2712. 